\title{
INCLUSÃO ESCOLAR E INFRAESTRUTURA FÍSICA DE ESCOLAS DE ENSINO FUNDAMENTAL
}

Camila Elidia Messias dos Santos ${ }^{1}$

Dera Lucia Messias Fialho CapelliniII

I Universidade Estadual Paulista "Júlio de Mesquita Filho" (Unesp), Bauru (SP), Brasil; kmila_messias@hotmail.com

II Universidade Estadual Paulista "Júlio de Mesquita Filho" (Unesp), Bauru (SP), Brasil; vera.capellini@unesp.br

\section{Resumo}

Este artigo tem como objetivo verificar as condições da infraestrutura física das escolas de um sistema municipal de ensino fundamental, considerando os alunos público-alvo da educação especial. O delineamento utilizado foi o qualitativo descritivo. Participaram da pesquisa 16 gestores das escolas municipais de ensino fundamental da cidade de Bauru, São Paulo. Os instrumentos utilizados foram o roteiro de observação do espaço físico e recursos inclusivos do contexto escolar e o roteiro de entrevista para os gestores escolares. Os resultados apontaram que a análise in loco difere do ponto de vista dos gestores. No entanto, há concordância sobre a necessidade de ampliação e melhoria da infraestrutura física, maior disponibilidade de recursos materiais e recursos adaptados, principalmente na classe comum.

ACESSIBILIDADE • EDUCAÇÃO ESPECIAL • INCLUSÃO ESCOLAR • ESCOLAS

\section{SCHOOL INCLUSION AND PHYSICAL INFRASTRUCTURE OF ELEMENTARY SCHOOL Abstract}

This paper aimed to verify the conditions of the physical infrastructure of schools in a Municipal Elementary School System, considering the target students of Special Education. The design used was the qualitative of the descriptive type. 16 managers of municipal elementary schools in the city of Bauru, São Paulo participated in the research. The instruments used were the script for observing the physical space and inclusive resources of the school context and the interview script for school managers. The results showed that the analysis in loco differs from the standpoint of the managers. However, both agree on the need to expand and improve the physical infrastructure, greater availability of material resources and adapted resources, principally in the common class.

\section{ACCESSIBILITY $• \mathrm{SPECIAL} \mathrm{EDUCATION} \cdot \mathrm{SCHOOL} \mathrm{INCLUSION} \cdot \mathrm{SCHOOLS}$}




\section{INCLUSIÓN ESCOLAR E INFRAESTRUCTURA FÍSICA DE ESCUELAS DE EDUCACIÓN FUNDAMENTAL}

\section{Resumen}

El propósito de este artículo es verificar las condiciones de la infraestructura física de las escuelas de un sistema municipal de educación fundamental, considerando a los alumnos como público objetivo de la educación especial. El delineamiento que se utilizó fue el cualitativo del tipo descriptivo. Participaron en el estudio 16 administradores de las escuelas municipales de educación fundamental de la ciudad de Bauru, São Paulo. Los instrumentos utilizados fueron el guión de observación del espacio físico y de los recursos inclusivos del ámbito escolar y el guión de entrevista para los administradores escolares. Los resultados señalaron que el análisis in loco difiere desde el punto de vista de los gestores. Sin embargo, hay concordancia sobre la necesidad de ampliar y mejorar la infraestructura física, una mayor disponibilidad de recursos materiales y recursos adaptados, sobre todo en la clase común.

ACCESIBILIDAD・EDUCACIÓN ESPECIAL・INCLUSIÓN ESCOLAR・ESCUELAS

\section{INCLUSION SCOLAIRE ET INFRASTRUCTURE PHYSIQUE DES ÉCOLES}

\section{Résumé}

L'objectif de cet article a été de vérifier les conditions relatives à l'infrastructure physique des écoles d'un réseau municipal, pour l'accueil des élèves cibles de l'éducation spécialisée. L'étude a utilisé une approche qualitative et descriptive, menée auprès de 16 directeurs d'écoles communales de la ville de Bauru, São Paulo. Un guide d'observation de l'espace physique et des ressources inclusives en contexte scolaire, ainsi q'une feulle de route pour l'entretien des gestionnaires scolaires ont été utilisés. Les résultats ont montré que l'analyse in loco diffère selon les gestionnaires. Néanmoins, il y a un accord sur le besoin non seulement d'élargir et d'améliorer l'infrastructure physique, mais aussi de disponibiliser davantage de ressources matérielles et de ressources adaptées, surtout dans les classes communes.

ACCESSIBILITÉ • ÉDUCATION SPÉCIALE • INCLUSION SCOLAIRE • ÉCOLES 
A DÉCADA DE 1990, COM A ASSINATURA DE DOCUMENTOS INTERNACIONAIS E A EXPANSÃO da legislação sobre o direito à escolarização dos alunos com deficiência, sobretudo a Conferência Mundial sobre Educação para Todos (Organização das Nações Unidas para a Educação, Ciência e Cultura [Unesco], 1990), a Declaração de Salamanca (Unesco, 1994), a Lei de Diretrizes e Bases da Educação Nacional (Lei n. 9.394, de 20 de dezembro de 1996) e a Política Nacional de Educação Especial na Perspectiva da Educação Inclusiva (2008), respaldadas por políticas públicas educacionais, estendeu-se o paradigma de educação especial para o princípio da educação inclusiva.

A inclusão escolar versa sobre o fortalecimento do processo de ensino-aprendizagem pautada em direitos humanos, no sentido de responder às necessidades, habilidades e características de todos, incluindo discussões e desdobramentos necessários para aprendizagem bem-sucedida do público-alvo da educação especial (PAEE) ${ }^{1}$ nas escolas comuns de ensino regular (Unesco, 2008; Fonseca et al., 2018). Contudo, a inserção desses alunos nas escolas, principalmente aqueles com deficiência ou mobilidade reduzida, tem demandado mudanças na organização dos espaços escolares (Silva Filho \& Kassar, 2019), devido à observância de estrutura física e materiais preocupantes (Monteiro \& Silva, 2015; Silva Filho \& Kassar, 2019), que frequentemente constituem empecilhos à sua utilização.

Desde então, a temática da infraestrutura escolar tem sido objeto de investigação de estudiosos (Satyro \& Soares, 2007; Soares Neto et al.,2013; Sá\& Werle,2017; Santos, 2019).Segundoo Censo Escolar 2018, a rede municipal é responsável por aproximadamente dois terços da educação básica (Ministério da Educação [MEC], 2019). No entanto, estudos revelam que somente 0,6\% dessas escolas têm infraestrutura adequada e congruente aos propósitos de uma educação de qualidade (Soares Neto et al., 2013). Gallo et al. (2011), ao analisarem as condições de acessibilidade das pessoas com deficiência física em 27 escolas de um município de Santa Catarina, utilizando um protocolo com questões sobre acessibilidade, espaço físico, mobiliário e edificações, observaram que nenhuma das escolas analisadas estava adaptada em todos os itens avaliados: 17 delas não tinham rampas de acesso, 14 não contavam com banheiros adaptados, 16 não tinham bebedouros adaptados, e nenhuma dispunha de sinalização para deficientes físicos.

De acordo com Moraes (2007), verificam-se constantemente nas escolas obstáculos e barreiras arquitetônicas, calçadas esburacadas e inexistência de rampas de acesso, sinalização e sanitários adequados, demonstrando a importância não só de se possibilitar o acesso ao interior dessas edificações, mas também de adaptar as condições das vias, estacionamentos e eliminar o máximo de barreiras que dificultam a circulação das pessoas. Além disso, a organização de edifícios escolares compostos por salas de aula tradicionais, pouca diversidade de arranjo mobiliário e uso restrito de equipamentos didáticos tende a prejudicar sua funcionalidade, que está mais associada a aspectos do dimensionamento dos ambientes, dos equipamentos, mobiliários e da variedade de ambientes disponíveis para o atendimento de todos os alunos (Kowaltowski, 2014).

Satyro e Soares (2007) destacam ainda que carências no contexto escolar, como prédios e instalações inadequados, inexistência de bibliotecas, espaços esportivos e laboratórios, baixo acesso a livros didáticos e materiais de leitura, tamanho inadequado de sala de aula e número elevado de alunos, tendem a influenciar diretamente o desempenho dos alunos e, consequentemente, o trabalho 
dos professores (Kimura, 2008). Isso implica a necessidade de conhecer as condições das escolas do país, em especial as públicas, responsáveis por $90 \%$ das matrículas do ensino fundamental (Satyro \& Soares, 2007).

A fim de minimizar essas desigualdades, desde 2008, a Política Nacional de Educação Especial na Perspectiva da Educação Inclusiva (2008) vem destacando a urgência de repensar a construção de sistemas educacionais que demandem uma mudança estrutural e cultural da escola, em que todos os estudantes tenham suas especificidades atendidas, segundo o Desenho Universal. De acordo com o Instituto Nacional para a Reabilitação (2014), o Desenho Universal ou "Desenho para Todos" tem como finalidade simplificar a vida de pessoas com ou sem deficiência, independentemente da idade, estatura ou capacidade, ao criar produtos, estruturas, mobiliários, equipamentos, comunicação/ informação e edificações que permitam a equiparação de oportunidades para que todos possam partilhar plenamente da vida em sociedade com autonomia, independência e segurança.

Conforme o Instituto Nacional para a Reabilitação (2014), a realização de um projeto de Desenho Universal deve contemplar sete princípios básicos:

- Utilização equitativa - pode ser utilizado por qualquer grupo.

- Flexibilidade de utilização - engloba uma gama extensa de preferências e capacidades individuais.

- Utilização simples e intuitiva - fácil de compreender, independentemente da experiência do utilizador.

- Informação perceptível - fornece de forma eficaz, ao utilizador, a informação necessária, independentemente das condições ambientais/físicas existentes ou as capacidades sensoriais do utilizador.

- Tolerância ao erro - minimiza riscos e consequências negativas decorrentes de ações acidentais ou involuntárias.

- Esforço físico mínimo - pode ser utilizado de forma eficaz e confortável com o mínimo de fadiga.

- Dimensão e espaço de abordagem e de utilização - espaço e dimensão adequados para abordagem, manuseio e utilização, independentemente da estatura, mobilidade ou postura do utilizador.

Para isso, o MEC tem ofertado apoio técnico e financeiro para adequações arquitetônicas nos prédios escolares e para a produção e distribuição dos recursos "materiais didáticos e paradidáticos em braille, áudio e língua brasileira de sinais (Libras), laptops com sintetizador de voz, softwares para comunicação alternativa e outras ajudas técnicas que possibilitam o acesso ao currículo" (Decreto n.7.611, de 17 de novembro de 2011, p. 3). Esses recursos são mediados pelo Programa Escola Acessível (PEA), que tem financiado a adequação arquitetônica das escolas, com a construção de rampas, sanitários e vias de acesso, instalação de corrimão e sinalização visual, tátil e sonora, assim como a aquisição de cadeiras de rodas, recursos de tecnologia assistiva, bebedouros e mobiliários acessíveis (MEC, 2013). Seu objetivo consiste em promover a inclusão de alunos com deficiência, transtornos globais do desenvolvimento e altas habilidades/superdotação matriculados em classes comuns do ensino regular, garantindo-lhes acessibilidade que possibilite o direito de compartilharem os espaços comuns de aprendizagem por meio de acesso ao ambiente físico, aos recursos didáticos e pedagógicos e às comunicações e informações (Decreto n. 7.611, de 17 de novembro de 2011). Entretanto, a realidade atual tem demonstrado as dificuldades em se garantir a inclusão de fato (Gallo et al., 2011; Médice et al., 2015; Santos, 2019; Silva Filho \& Kassar, 2019).

Médice et al. (2015), com o objetivo de identificar e descrever as barreiras arquitetônicas em 14 escolas municipais de ensino fundamental de uma cidade do oeste do estado de São Paulo, utilizaram um protocolo padronizado para mapear as condições arquitetônicas de acesso. Os resultados apontaram que as 14 escolas visitadas não tinham piso antiderrapante e piso tátil nos diversos setores analisados, as dimensões, a empunhadura e o deslizamento dos corrimões eram inadequados, as escadas não estavam associadas a rampas, e os sanitários não tinham área de transferência, espelhos e lavatórios adaptados. 
Em outro estudo, Silva Filho e Kassar (2019) observaram que 16 de 17 escolas de um município que receberam adaptações para o atendimento aos alunos PAEE continuavam com um conjunto de espaços fora dos padrões propostos pelas normas técnicas que, em sua maioria, inviabilizavam completamente o seu uso.

Diante de tais levantamentos e da importância que o tema representa para a área educacional, principalmente se comparado aos estudos internacionais, as pesquisas brasileiras contam com informações menos detalhadas sobre o ambiente escolar, o que sugere a necessidade de instrumentos que especifiquem esses aspectos ou estudos in loco (Unesco, 2019). O presente artigo tem como objetivo verificar as condições da infraestrutura física das escolas de um sistema municipal de ensino fundamental, considerando os alunos PAEE, tendo como base duas perguntas norteadoras: o sistema municipal de ensino fundamental tem infraestrutura adequada para receber os alunos PAEE, segundo o ponto de vista dos gestores? O sistema municipal de ensino fundamental tem infraestrutura adequada para receber os alunos PAEE, segundo observação in loco?

Por fim, ressalta-se a contribuição da pesquisa por ser realizada in loco nas 16 escolas municipais de ensino municipal da cidade e pela possibilidade de comparações possíveis, por escolas e por itens, demonstrando os pontos que mais precisam de atenção para a construção de uma escola de qualidade.

\section{Método}

Trata-se de uma pesquisa qualitativa do tipo descritiva. ${ }^{2}$ De acordo com Gil (2010), as pesquisas descritivas têm como principal objetivo a descrição das características da população em estudo ou do fenômeno, ou o estabelecimento de relações entre variáveis. O delineamento escolhido foi a observação naturalística e/ou de campo, que consiste na observação direta do grupo estudado e na realização de entrevistas com os sujeitos do local para compreender suas representações do que acontece em sua realidade (Cozby, 2003).

Participaram da pesquisa 16 gestores de escolas municipais de ensino fundamental da cidade de Bauru, São Paulo, sendo 15 do sexo feminino e um do sexo masculino. Foi critério de inclusão a participação de um gestor de cada escola municipal de ensino fundamental. Para identificação dos participantes foi utilizada a letra inicial da função gestor, seguida do número sequencial em que as escolas foram visitadas (G1, G2, G3, e assim consecutivamente).

A cidade de Bauru localiza-se na região centro-oeste paulista. Segundo o Instituto Brasileiro de Geografia e Estatística (IBGE), em 2010, no munícipio havia 343.937 habitantes, sendo estimada, para 2018, uma população de 374.272 pessoas. A área que compõe a unidade territorial da cidade corresponde a $667,684 \mathrm{~km}^{2}$, e a densidade demográfica é de 515,12 hab. $/ \mathrm{km}^{2}$ (IBGE, 2017).

De acordo com os dados da Secretaria Municipal de Educação, ${ }^{3}$ o sistema municipal de ensino é composto por 66 escolas municipais de ensino infantil (Emei), 16 escolas municipais de ensino fundamental (Emef) e três centros de educação de jovens e adultos (Ceja). Desde 2005, a cidade adota os serviços de educação especial na perspectiva da educação inclusiva em seu sistema regular de ensino, a fim de ofertar aos alunos PAEE o atendimento educacional especializado nas salas de recursos multifuncionais, onde o professor especialista suplementa o ensino aos alunos com altas habilidades/superdotação e o complementa para aqueles com deficiência e transtorno global do desenvolvimento. Em 2017, ano de coleta de dados da pesquisa, as 16 Emefs eram responsáveis por 8.477 das matrículas do município, das quais 147 eram alunos PAEE e 24 estavam em processo de avaliação.

2 O presente estudo é parte integrante da pesquisa Avaliação da qualidade da educação ofertada aos alunos público-alvo da educação especial em escolas públicas da comarca de Bauru (Capellini, 2018), subsidiada pela Fundação de Amparo à Pesquisa do Estado de São Paulo (Fapesp, processo 2015/22397-5), aprovada pelo Comitê de Ética em Pesquisa da Faculdade de Ciências da Universidade Estadual Paulista "Júlio de Mesquita Filho" (Unesp), campus de Bauru, de acordo com a Resolução n. 466, de 12 de dezembro de 2012 e autorizada pelo Comitê de Ética da Secretaria de Educação da cidade onde se realizou este estudo.

3 Dados fornecidos pela Secretaria Municipal de Educação (2017, não publicado). 
A pesquisa foi realizada nas 16 escolas municipais de ensino fundamental da cidade de Bauru. A identificação das escolas e o número de alunos e funcionários de cada uma são apresentados na Tabela 1.

\section{TABELA 1}

NÚMERO DE ALUNOS E FUNCIONÁRIOS NAS ESCOLAS MUNICIPAIS PESQUISADAS MUNICÍPIO DE BAURU - 2017

\begin{tabular}{|c|c|c|c|c|c|c|c|c|c|c|}
\hline 芩 & $\begin{array}{c}\text { Ano de } \\
\text { inauguração }\end{array}$ & $\begin{array}{c}\text { Ensino } \\
\text { fundamental }\end{array}$ & $\begin{array}{l}\mathrm{N}^{\circ} \text { de } \\
\text { salas }\end{array}$ & $\begin{array}{c}\mathrm{N}^{\circ} \text { total } \\
\text { de alunos }\end{array}$ & $\begin{array}{l}\mathrm{N}^{\circ} \text { de } \\
\text { alunos } \\
\text { PAEE }\end{array}$ & $\begin{array}{c}\text { Alunos } \\
\text { PAEE } \\
(\%)\end{array}$ & $\begin{array}{c}\mathrm{N}^{\circ} \\
\text { de } \\
\text { funcio- } \\
\text { nários }\end{array}$ & $\begin{array}{c}\text { Razão } \\
\text { alunos/ } \\
\text { funcionários }\end{array}$ & $\begin{array}{c}\mathrm{N}^{\circ} \\
\text { de } \\
\text { docentes }\end{array}$ & $\begin{array}{c}\text { Razão } \\
\text { alunos/ } \\
\text { docentes }\end{array}$ \\
\hline E1 & 1990 & I e II & 18 & 476 & 12 & 2,5 & 21 & 22,6 & 27 & 17,6 \\
\hline E2 & 1998 & I & 16 & 430 & 3 & 0,6 & 15 & 28,6 & 26 & 16,5 \\
\hline E3 & 2004 & I & 20 & 582 & 3 & 0,5 & 15 & 38,8 & 34 & 17,1 \\
\hline E4 & 1986 & I e II & 26 & 558 & 15 & 2,6 & 16 & 34,8 & 44 & 12,6 \\
\hline E5 & 1998 & I & 14 & 339 & 5 & 1,4 & 10 & 33,9 & 20 & 16,9 \\
\hline E6 & 2002 & I & 20 & 598 & 8 & 1,3 & 13 & 46 & 28 & 21,3 \\
\hline E7 & 2012 & I & 22 & 584 & 11 & 1,8 & 21 & 27,8 & 35 & 16,6 \\
\hline E8 & 1988 & I e II & 36 & 887 & 15 & 1,6 & 20 & 44,3 & 59 & 15 \\
\hline E9 & 2002 & I e II & 18 & 460 & 15 & 3,2 & 16 & 28,7 & 33 & 13,9 \\
\hline E10 & 2008 & I & 23 & 623 & 13 & 2,0 & 14 & 44,5 & 39 & 15,9 \\
\hline E11 & 1983 & I e II & 21 & 560 & 10 & 0,1 & 40 & 14 & 13 & 43 \\
\hline E12 & 2005 & I & 18 & 455 & 5 & 1,0 & 12 & 37,9 & 28 & 16,2 \\
\hline E13 & 2008 & I & 18 & 511 & 11 & 2,1 & 13 & 39,3 & 30 & 17 \\
\hline E14 & 2004 & I & 22 & 556 & 6 & 1,0 & 18 & 30,8 & 37 & 15 \\
\hline E15 & 2000 & I & 22 & 532 & 8 & 1,5 & 12 & 44,3 & 36 & 14,7 \\
\hline E16 & 2005 & I & 13 & 326 & 7 & 2,1 & 8 & 40,7 & 25 & 13 \\
\hline
\end{tabular}

Fonte: Elaboração das autoras com base nos dados da Secretaria Municipal de Educação (2017, não publicado).

\section{Coleta de dados}

$O$ roteiro de observação do espaço físico e recursos inclusivos do contexto escolar foi adaptado por Santos (2019) do Inventário de observação em creches de Mendes (2002). O roteiro é constituído por 34 itens estruturados, divididos em cinco subitens (acesso de entrada, sala de aula, banheiro, refeitório e outros recursos) e questões para caracterização do contexto escolar, incluindo data de inauguração da escola, número total de alunos, de alunos PAEE, de classes, de funcionários e de docentes. No entanto, no presente estudo, os dados referentes ao banheiro foram descartados por considerar que nas escolas de ensino fundamental não havia necessidade de adaptação das dimensões das pias e vasos sanitários ao tamanho das crianças.

$O$ roteiro de entrevista para os gestores escolares corresponde a um roteiro de entrevista semiestruturado, elaborado por Santos (2019) para os gestores escolares, contendo duas questões sobre como consideram as condições do espaço físico escolar e quais as possíveis melhorias para o contexto.

Após a aprovação pelo Comitê de Ética em pesquisa da Faculdade de Ciências, Unesp, campus de Bauru, e pela Secretaria de Educação do Município onde se realizou o estudo, a pesquisadora elaborou um cronograma de visita às escolas entre abril e julho de 2017 e encaminhou à Secretaria de Educação da cidade, para ciência prévia da direção da escola sobre o dia e o horário para a coleta de dados. 
No dia combinado, a pesquisadora compareceu à escola para coleta de dados, durante aproximadamente 40 a 90 minutos. Após apresentação dos objetivos da pesquisa e esclarecimento das dúvidas, o gestor escolar disponível foi convidado a participar da entrevista.

Os participantes que aceitaram o convite assinaram o Termo de Consentimento Livre e Esclarecido (TCLE) e, em local reservado e sigiloso, responderam à entrevista. O gravador de áudio foi utilizado para gravar as respostas (nos casos em que os participantes não autorizaram a gravação da entrevista, a pesquisadora escreveu as respostas dos participantes). Em seguida, acompanhada de algum funcionário da escola ou do próprio gestor escolar, a pesquisadora analisou in loco as condições da infraestrutura física da escola, com coleta de imagens via celular e preenchimento do roteiro de observação do espaço físico e recursos inclusivos do contexto escolar.

\section{Análise dos dados}

Para análise dos dados do roteiro de observação, um valor específico (de meio ponto a dois) foi atribuído a cada item das categorias de análise, conforme sua relevância (Quadro 1), totalizando dez pontos por categoria. Após a soma dos resultados obtidos em cada categoria, o escore total foi dividido pelo número de categorias analisadas $(n=4)$ e atribuiu-se uma nota geral para cada escola, classificando como inadequadas as que obtiveram pontuações de 0 a 5 , como parcialmente adequadas as com pontuações de 5,1 a 7,9 e adequadas aquelas com pontuações de 8,0 a 10.

\section{QUADRO 1}

PONTUAÇÕES DE CADA ITEM DAS CATEGORIAS DO "ROTEIRO DE OBSERVAÇÃO DO ESPAÇO FÍSICO E RECURSOS INCLUSIVOS DO CONTEXTO ESCOLAR"

\begin{tabular}{|c|c|c|c|c|c|c|c|c|}
\hline \multicolumn{9}{|c|}{ CATEGORIAS DE ANÁLISE } \\
\hline Item & ACESSO & escore & SALA DE AULA & escore & REFEITÓRIO & escore & OUTROS & escore \\
\hline 1 & $\begin{array}{l}\text { Percursos } \\
\text { sinalizados }\end{array}$ & 1,5 & Sala arejada & 1,0 & $\begin{array}{l}\text { Tamanho } \\
\text { de mesas e } \\
\text { cadeiras }\end{array}$ & 2,0 & $\begin{array}{l}\text { Atividades } \\
\text { desenhadas } \\
\text { no chão }\end{array}$ & 1,0 \\
\hline 2 & $\begin{array}{c}\text { Sinalização em } \\
\text { braille/Libras }\end{array}$ & 1,5 & Iluminação & 1,0 & $\begin{array}{l}\text { Distância } \\
\text { entre os } \\
\text { móveis }\end{array}$ & 2,0 & $\begin{array}{l}\text { Cartazes ou } \\
\text { mural com } \\
\text { trabalhos }\end{array}$ & 1,0 \\
\hline 3 & $\begin{array}{l}\text { Percursos } \\
\text { iluminados }\end{array}$ & 0,5 & $\begin{array}{l}\text { Baixo nível de } \\
\text { ruído }\end{array}$ & 1,0 & $\begin{array}{l}\text { Número de } \\
\text { crianças por } \\
\text { mesa }\end{array}$ & 2,0 & Palco & 1,0 \\
\hline 4 & $\begin{array}{l}\text { Percursos livres } \\
\text { de obstáculos }\end{array}$ & 1,5 & $\begin{array}{l}\text { Dimensão das } \\
\text { salas }\end{array}$ & 1,0 & $\begin{array}{l}\text { Utensílios } \\
\text { em bom } \\
\text { estado de } \\
\text { conservação }\end{array}$ & 2,0 & Sala de vídeo & 1,5 \\
\hline 5 & $\begin{array}{c}\text { Acesso externo } \\
\text { adequado }\end{array}$ & 1,5 & $\begin{array}{l}\text { Áreas definidas } \\
\text { por tapetes e } \\
\text { capachos }\end{array}$ & 1,0 & $\begin{array}{l}\text { Necessidade } \\
\text { de a criança } \\
\text { esperar à mesa }\end{array}$ & 2,0 & Biblioteca & 1,5 \\
\hline 6 & Piso tátil & 1,5 & $\begin{array}{c}\text { Tamanho e } \\
\text { disposição dos } \\
\text { móveis }\end{array}$ & 1,0 & & & Elevador & 1,0 \\
\hline 7 & $\begin{array}{c}\text { Piso } \\
\text { antiderrapante }\end{array}$ & 1,5 & $\begin{array}{l}\text { Diversidade de } \\
\text { materiais }\end{array}$ & 2,0 & & & $\begin{array}{c}\text { Atividades } \\
\text { diferenciadas }\end{array}$ & 1,5 \\
\hline 8 & $\begin{array}{l}\text { Proximidade da } \\
\text { equipe gestora }\end{array}$ & 0,5 & $\begin{array}{l}\text { Equipamentos } \\
\text { necessários para } \\
\text { alunos PAEE }\end{array}$ & 2,0 & & & Parquinho & 1,5 \\
\hline
\end{tabular}

Fonte: Elaboração das autoras com a pontuação sugerida por Mendes (2002).

As entrevistas foram transcritas integralmente e tratadas conforme a análise temática. Essa análise pode ser graficamente apresentada por meio de uma palavra, de uma frase ou de um resumo, 
visando a desvendar os núcleos de sentido da comunicação, cuja presença e frequência signifiquem alguma coisa para o objeto analítico escolhido (Bardin, 2011).

\section{Resultados e discussões}

Os resultados obtidos pelo roteiro de observação do espaço físico e recursos inclusivos do contexto escolar foram agrupados em categorias de análise, a saber: acesso de entrada, sala de aula, refeitório e outros recursos. Os critérios utilizados para pontuação dos itens seguiram as orientações para a eliminação das barreiras e garantia de acesso a todos os alunos, de acordo com o Manual de acessibilidade espacial para escolas: o direito à escola acessivel (MEC, 2009). Os resultados desse instrumento serviram de critério para avaliação das escolas, no entanto, por se tratar de um instrumento com itens estruturados, preenchidos pela pesquisadora, podem ser interpretados diferentemente, de acordo com a subjetividade do avaliador.

Desse modo, as análises realizadas in loco por meio do roteiro de observação do espaço físico e recursos inclusivos do contexto escolar permitiram verificar e comparar a adequabilidade de cada categoria ao atendimento de alunos PAEE e contrapor ao ponto de vista dos gestores apresentado no roteiro de entrevista para os gestores escolares, com o objetivo de traçar metas e estratégias para a melhoria das condições de inclusão escolar. A análise in loco realizada pela avaliadora considerou as pontuações obtidas em cada categoria, ao passo que a avaliação dos gestores consistiu no seu ponto de vista em relação aos aspectos da escola, mas também categorizando-os como adequados, inadequados e adequados em partes.

De modo geral, as condições de acesso de entrada às escolas foram as menos adaptadas e, por isso, tiveram menor pontuação nos itens percursos sinalizados, sinalização em braille/Libras, piso tátil e piso antiderrapante. As salas de aulas eram apertadas, com pouca ventilação e alto nível de ruído. Os refeitórios atendiam aos critérios analisados, e 14 das 16 escolas tinham outros recursos complementares à inclusão dos alunos. Entretanto, observou-se que nenhuma escola foi planejada visando a atender a todos e, apesar de algumas adequações na infraestrutura física terem sido realizadas, muito ainda precisa ser melhorado para serem consideradas de qualidade e totalmente adequadas ao atendimento de alunos PAEE. Para compreender essas necessidades, as análises realizadas em cada item são apresentadas a seguir.

\section{Acesso de entrada}

Foram itens de análise dessa categoria: percursos sinalizados, sinalização em braille/Libras, percursos iluminados, percursos livres de obstáculos, acesso externo adequado, piso tátil, piso antiderrapante e proximidade de acesso à equipe gestora.

TABELA 2

PONTUAÇÕES ATRIBUIIDAS ÀS CONDIÇÕES DE ACESSO DAS ESCOLAS

\begin{tabular}{|c|c|c|c|c|c|c|c|c|c|c|c|c|c|c|c|c|}
\hline \multicolumn{17}{|c|}{ ESCOLAS } \\
\hline ITENS & 1 & 2 & 3 & 4 & 5 & 6 & 7 & 8 & 9 & 10 & 11 & 12 & 13 & 14 & 15 & 16 \\
\hline Percursos sinalizados & 0 & 0 & 0 & 0 & 0 & 0 & 0 & 0 & 0 & 0 & 0 & 0 & 0 & 0 & 0 & 0 \\
\hline $\begin{array}{c}\text { Sinalização em braille/ } \\
\text { Libras }\end{array}$ & 0 & 0 & 0 & 0 & 0 & 0 & 0 & 0 & 0 & 0 & 0 & 0 & 0 & 0 & 0 & 0 \\
\hline Percursos iluminados & 0 & 0,5 & 0,5 & 0 & 0,5 & 0,5 & 0,5 & 0,5 & 0,5 & 0,5 & 0,5 & 0,5 & 0,5 & 0,5 & 0,5 & 0,5 \\
\hline $\begin{array}{l}\text { Percursos livres de } \\
\text { obstáculos }\end{array}$ & 0 & 1,5 & 1,5 & 1,5 & 1,5 & 1,5 & 1,5 & 1,5 & 1,5 & 1,5 & 1,5 & 1,5 & 1,5 & 1,5 & 1,5 & 1,5 \\
\hline $\begin{array}{l}\text { Acesso externo } \\
\text { adequado }\end{array}$ & 1,5 & 1,5 & 1,5 & 1,5 & 0 & 1,5 & 1,5 & 1,5 & 1,5 & 1,5 & 1,5 & 1,5 & 1,5 & 1,5 & 1,5 & 1,5 \\
\hline
\end{tabular}




\begin{tabular}{|c|c|c|c|c|c|c|c|c|c|c|c|c|c|c|c|c|}
\hline \multicolumn{17}{|c|}{ ESCOLAS } \\
\hline ITENS & 1 & 2 & 3 & 4 & 5 & 6 & 7 & 8 & 9 & 10 & 11 & 12 & 13 & 14 & 15 & 16 \\
\hline Piso tátil & 0 & 1,5 & 0 & 0 & 0 & 0 & 0 & 0 & 1,5 & 0 & 0 & 0 & 0 & 0 & 0 & 0 \\
\hline Piso antiderrapante & 1,5 & 0 & 0 & 0 & 0 & 0 & 0 & 0 & 0 & 0 & 0 & 0 & 0 & 0 & 1,5 & 0 \\
\hline $\begin{array}{l}\text { Proximidade de } \\
\text { acesso à equipe } \\
\text { gestora }\end{array}$ & 0,5 & 0,5 & 0 & 0,5 & 0,5 & 0,5 & 0,5 & 0,5 & 0 & 0,5 & 0 & 0 & 0 & 0,5 & 0,5 & 0 \\
\hline NOTA & 3,5 & 5,5 & 3,5 & 3,5 & 2,5 & 4,0 & 4,0 & 4,0 & 5,0 & 4,0 & 3,5 & 3,5 & 3,5 & 4,0 & 5,5 & 3,5 \\
\hline
\end{tabular}

Fonte: Elaborado pelas autoras com os dados observados nas escolas.

$\mathrm{Na}$ categoria acesso de entrada, a média das escolas foi de 3,9 pontos. A escola 5 teve a menor pontuação (2,5 pontos) e as escolas 2 e 15 , as maiores pontuações (5,5 pontos). Nenhuma escola foi pontuada nos itens percursos sinalizados e sinalização em braille/Libras, porém 15 das 16 escolas apresentaram percursos livres de obstáculos e acesso externo adequado.

Os percursos das escolas seriam considerados sinalizados caso tivessem placas indicativas para orientação de saídas, escadas, rampas, identificação em letras grandes, com contraste de cor e relevo junto às portas dos diferentes ambientes, para indicar a que atividades se destinam, e contraste de cor entre piso, parede e portas para facilitar a orientação das pessoas (MEC, 2009). No entanto, como todas as escolas visitadas tinham apenas identificação nas portas das salas de aula, esse item não foi considerado suficiente para pontuação, uma vez que a sinalização se limita ao local, não estando presente no percurso. Resultados semelhantes também foram encontrados por Gallo et al. (2011), que, ao analisarem as condições de 27 escolas do município de Chapecó, observaram a inexistência de qualquer sinalização para pessoas com deficiência, bem como por Basei e Cavasini (2015), que, das 20 escolas analisadas, verificaram que $95 \%$ não tinham qualquer tipo de sinalização.

As escolas seriam consideradas sinalizadas caso tivessem placas em braille ao lado das portas e na altura das mãos e placas em Libras, identificando os ambientes (MEC, 2009). A sinalização em Libras foi encontrada em uma das escolas (E3), identificando o espaço como sala de informática; porém, como o local era utilizado como depósito, a escola não foi pontuada, por se tratar de uma casualidade, e não porque ela estivesse adaptada a esse quesito ou a qualquer outro tipo de sinalização, como o braille. Esse resultado corrobora os achados de Gallo et al. (2011), que também não encontraram qualquer tipo de sinalização para as pessoas com deficiência em seu estudo. Conforme Manzini e Corrêa (2008) destacam, a falta de alguns elementos pode intensificar as desvantagens vivenciadas pelas pessoas com deficiência, visto que a inexistência de sinalização em braille/Libras impossibilita a informação e o acesso dos alunos com deficiência visual aos diversos espaços escolares.

Os percursos foram considerados iluminados quando as escolas apresentavam boa claridade, incluindo os corredores e escadas. Desse modo, a iluminação foi classificada como insuficiente em duas escolas (E1 e E4), por terem corredores sem janelas e com poucas lâmpadas, principalmente nas escolas que tinham edifícios verticais, com mais de um andar.

Os percursos foram considerados livres de obstáculos quando eram pavimentados, com piso regular e livres de obstáculos (MEC, 2009). Na escola 1, os percursos internos não eram livres de obstáculos, pois o corredor de acesso à quadra de esportes tinha piso irregular e uma árvore em sua rota. A presença de árvores protegidas por algum tipo de suporte ou sem proteção já havia sido identificada no estudo de Corrêa e Manzini (2012) como um dos principais obstáculos encontrados nas rotas escolares. Esse fato se destaca, pois, ao planejar ambientes acessíveis, deve-se atentar para a localização de cada elemento, visto que, quando mal localizados, atrapalham a passagem e tornam-se barreiras para pessoas com deficiência, principalmente aquelas com deficiência visual (MEC, 2009). 
O acesso externo foi considerado adequado quando a rua da escola era asfaltada, tinha faixa de pedestre, guias rebaixadas, ponto de ônibus próximo e calçada pavimentada, sem buracos, degraus e/ou obstáculos (MEC, 2009). Na escola 5, apesar de terem sido identificadas condições que possibilitassem maior acessibilidade aos alunos, como a presença de rua asfaltada e ponto de ônibus próximo à escola, percebeu-se que não eram realizados reparos na sua infraestrutura, devido aos obstáculos (buracos, terra e desnivelamento na calçada) prejudicarem o livre acesso das pessoas com deficiência. De acordo com Miron e Costa (2014), a falta de conservação do piso das calçadas é frequentemente observada. Castro et al. (2018) acrescentam que a carência de condições adequadas à acessibilidade não só restringe a participação dos indivíduos com deficiência, mas também prejudica o acesso a uma educação igualitária de qualidade, delimitando o desenvolvimento das suas potencialidades e a melhoria da qualidade de vida desses sujeitos.

O piso tátil seria considerado adequado caso a escola tivesse mapa tátil que representasse o esquema da escola (MEC, 2009). No entanto, como somente as escolas 2 e 9 apresentaram piso tátil em rota parcial, o critério considerado foi ter esse tipo de piso em rota total ou parcial. Na escola 9, o piso tátil estava instalado somente do portão de entrada até a sala de recursos, reiterando os achados de Corrêa e Manzini (2012), que encontraram poucas linhas-guias nas escolas avaliadas e, na maioria delas, as linhas não se apresentavam em todo o percurso.

O piso antiderrapante foi considerado adequado na escola que tivesse esse tipo de piso regular e em boas condições (MEC, 2009) em rota parcial ou total. No interior da escola 4, verificou-se a presença de piso liso e áspero nos corredores das salas de aula e piso áspero nos demais, demonstrando a escassez de piso antiderrapante nas escolas analisadas, encontrado apenas nas escolas 1 e 5.

Esses resultados corroboram com o estudo de Castro et al. (2018), Manzini e Corrêa (2008) e Corrêa e Manzini (2012), em que essa condição foi pouco encontrada nas escolas avaliadas. Os autores ratificam ainda que as escolas, em sua maioria, tinham piso áspero e liso e que "o piso liso pode ser perigoso para os seus alunos, uma vez que pode se tornar escorregadio, principalmente quando molhado" (Corrêa \& Manzini, 2012, p. 8).

A proximidade de acesso à equipe gestora consiste na facilidade de o aluno contatá-la quando necessário. Desse modo, a proximidade foi considerada adequada quando as salas do diretor, vice-diretor e coordenador pedagógico eram compartilhadas, localizando-se uma ao lado da outra ou uma em frente à outra. A dificuldade ao acesso pode contribuir para a falta de participação dos alunos PAEE nesse setor escolar, entretanto seis escolas (E3, E9, E11, E12, E13 e E16) não tinham equipe gestora próxima.

\section{Sala de aula}

Foram itens de análise dessa categoria: sala arejada, iluminação, baixo nível de ruído, dimensão das salas, áreas definidas por tapetes e capachos, tamanho e disposição dos móveis, diversidade de materiais e equipamentos necessários para alunos PAEE.

TABELA 3

PONTUAÇÕES ATRIBUÍDAS ÀS CONDIÇÕES DA SALA DE AULA

\begin{tabular}{|c|c|c|c|c|c|c|c|c|c|c|c|c|c|c|c|c|}
\hline \multicolumn{17}{|c|}{ ESCOLAS } \\
\hline ITENS & 1 & 2 & 3 & 4 & 5 & 6 & 7 & 8 & 9 & 10 & 11 & 12 & 13 & 14 & 15 & 16 \\
\hline Sala arejada & 0 & 1,0 & 0 & 0 & 0 & 1,0 & 1,0 & 1,0 & 0 & 1,0 & 0 & 1,0 & 1,0 & 1,0 & 1,0 & 1,0 \\
\hline Sala iluminada & 1,0 & 1,0 & 1,0 & 1,0 & 1,0 & 1,0 & 1,0 & 1,0 & 1,0 & 1,0 & 1,0 & 1,0 & 1,0 & 1,0 & 0 & 1,0 \\
\hline $\begin{array}{l}\text { Baixo nível de } \\
\text { ruído }\end{array}$ & 0 & 0 & 0 & 0 & 0 & 0 & 0 & 0 & 0 & 0 & 0 & 1,0 & 0 & 1,0 & 1,0 & 1,0 \\
\hline $\begin{array}{l}\text { Dimensão da } \\
\text { sala }\end{array}$ & 0 & 0 & 0 & 0 & 0 & 0 & 1,0 & 1,0 & 1,0 & 1,0 & 0 & 1,0 & 1,0 & 1,0 & 1,0 & 1,0 \\
\hline
\end{tabular}




\begin{tabular}{|c|c|c|c|c|c|c|c|c|c|c|c|c|c|c|c|c|}
\hline \multicolumn{17}{|c|}{ ESCOLAS } \\
\hline ITENS & 1 & 2 & 3 & 4 & 5 & 6 & 7 & 8 & 9 & 10 & 11 & 12 & 13 & 14 & 15 & 16 \\
\hline $\begin{array}{l}\text { Tapetes e } \\
\text { capachos }\end{array}$ & 1,0 & 1,0 & 1,0 & 1,0 & 1,0 & 1,0 & 1,0 & 1,0 & 1,0 & 1,0 & 1,0 & 1,0 & 1,0 & 1,0 & 1,0 & 1,0 \\
\hline $\begin{array}{c}\text { Tamanho e } \\
\text { disposição dos } \\
\text { móveis }\end{array}$ & 1,0 & 1,0 & 1,0 & 1,0 & 1,0 & 1,0 & 1,0 & 1,0 & 1,0 & 1,0 & 1,0 & 1,0 & 1,0 & 1,0 & 1,0 & 1,0 \\
\hline $\begin{array}{c}\text { Diversidade de } \\
\text { materiais }\end{array}$ & 2,0 & 2,0 & 2,0 & 0 & 2,0 & 2,0 & 2,0 & 0 & 2,0 & 0 & 0 & 2,0 & 2,0 & 2,0 & 2,0 & 2,0 \\
\hline $\begin{array}{l}\text { Equipamentos } \\
\text { necessários }\end{array}$ & 2,0 & 2,0 & 2,0 & 2,0 & 2,0 & 2,0 & 2,0 & 2,0 & 2,0 & 2,0 & 2,0 & 2,0 & 2,0 & 2,0 & 2,0 & 2,0 \\
\hline NOTA & 7,0 & 8,0 & 7,0 & 5,0 & 7,0 & 8,0 & 9,0 & 7,0 & 8,0 & 7,0 & 5,0 & 10 & 9,0 & 10 & 9,0 & 10 \\
\hline
\end{tabular}

Fonte: Elaborado pelas autoras com os dados observados nas escolas.

Para análise desse item, o gestor que acompanhou a pesquisadora durante a visita à escola estabeleceu uma sala de aula a ser observada que estivesse com a turma em intervalo ou em atividade extraclasse. Nessa categoria, a média das escolas foi de 7,8 pontos. Três escolas (E12, E14 e E16) atenderam totalmente aos itens analisados (10 pontos) e duas (E4 e E11) tiveram a menor pontuação (5 pontos cada). Contudo, cabe destacar que o item baixo nível de ruído foi pontuado nas escolas 14,15 e 16 , mas essas não estavam em dia letivo.

As salas de aula observadas foram consideradas arejadas quando tinham janelas amplas (MEC, 2009) e portas localizadas em corredores abertos. Das 16 escolas, dez foram classificadas como arejadas (E2, E6, E7, E8, E10, E12, E13, E14, E15 e E16). Apesar disso, como a pesquisa foi feita em uma sala por escola, em virtude de a maior parte da coleta ter sido realizada durante o período letivo, as condições das salas de aula de uma mesma escola podiam ser diferentes, conforme sua localização.

As salas de aula foram consideradas iluminadas quando tinham janelas amplas que possibilitavam boa iluminação (MEC, 2009). Contudo, como verificado na (E15), dependendo do horário, a iluminação da sala de aula ficava extremamente prejudicada devido à claridade. A escola 14 implementou uma solução (pintura dos vidros das janelas e da porta), visando a diminuir essa dificuldade, em razão de a falta de iluminação adequada prejudicar o processo de aprendizagem dos alunos (Tada et al., 2012; Castro, 2000). No entanto, a solução adotada pela escola pode ser prejudicial à aprendizagem das crianças do outro período, uma vez que o ambiente ficará mais escuro; assim, a utilização de cortinas poderia ser mais útil para ambas as turmas.

Os ruídos no ambiente escolar foram considerados altos quando o barulho externo à sala de aula era superior ao da própria sala. Essa condição ocorreu em 12 escolas (E1, E2, E3, E4, E5, E6, E7, E8, E9, E10, E11 e 13), devido ao fato de os recreios serem fracionados de acordo com o ano escolar (cada escola tinha de três a quatro recreios por dia), provocando barulho no horário das aulas de quem não estivesse no intervalo naquele momento. A justificativa para tal divisão é o elevado número de alunos dessas escolas, que não comportariam todos ao mesmo tempo nos pátios. Em conformidade com Calado (2006), o ruído pode prejudicar as atividades nas salas de aula, sendo, portanto, imprescindível que os espaços escolares atendam às exigências básicas de conforto ambiental, entre elas o ruído mínimo e a iluminação adequada para a qualidade do trabalho a ser realizado (Castro, 2000).

A dimensão das salas foi considerada boa quando a distância entre as mesas possibilitava a circulação dos alunos sem dificuldade. Nove das 16 escolas analisadas atenderam ao critério, contrapondo os achados de Gallo et al. (2011), em que, das 27 escolas analisadas, 25 (92,59\%) tinham salas de aula amplas.

Segundo Teixeira e Reis (2012), a disposição das carteiras em U possibilita posição de destaque ao professor e maior mobilidade, propiciando sempre que necessário contato mais próximo com o aluno. 
Porém, tal configuração foi pouco encontrada nas escolas visitadas. Da mesma forma, Roquejani et al. (2018) complementam que, para responder às múltiplas diversidades em sala de aula, são necessárias variadas estratégias e formas de promover o ensino, assim como diferentes arranjos no espaço físico escolar.

As áreas foram consideradas adequadas quando não tinham espaços definidos por tapetes e/ou capachos. Segundo Manzini e Corrêa (2008), a análise desse item é importante, pois tapetes e capachos podem ser um empecilho aos alunos ou a outras pessoas que circulem pela escola, que podem tropeçar, cair e machucar-se. Portanto, como em nenhuma escola foi encontrado esse elemento, todas foram consideradas adequadas, assim como nos achados de Corrêa e Manzini (2012) e Corrêa (2010).

O tamanho e a disposição dos móveis foram considerados adequados quando havia mobiliário adequado à faixa etária das crianças (MEC, 2009), tendo todas as escolas atendido ao critério.

A diversidade de materiais foi classificada como adequada quando os gestores relataram ser suficiente (E1, E2, E3, E5, E6, E7, E9, E10, E12, E13, E14, E15 e E16). Destacou-se a existência de materiais de diferentes formas, cores, tamanhos, comodidade e praticidade, como lego, ursos de pelúcia, bonecas, jogos didáticos etc., mais precisamente nas salas de primeiro ano, sala de recursos ou alguma sala específica para guarda de materiais da escola. Apesar disso, três gestores apontaram a disponibilidade como insuficiente (G7, G8 e G10) e outros três (G8, G10 e G14) informaram que as escolas carecem de móveis adaptados.

A realidade das escolas visitadas permite supor que o processo de inclusão escolar ainda está em desenvolvimento. Como pressuposto elementar nas diretrizes e leis que apoiam essa ideia está a disponibilização de materiais que atendam às diferenças dos alunos (Decreto n. 7.611, de 17 de novembro de 2011), mas algumas vezes tal recurso não chega à escola que precisa. Essa situação agravase quando representantes escolares mencionaram não saber se existia carteira adaptada, e as escolas que a tinham não terem alunos utilizando-as.

Apesar da queixa da falta de materiais adaptados em algumas escolas, observou-se o empenho desses profissionais em atender e ofertar melhor atendimento a esse alunado. De acordo com o relato do G10, para conseguir trocar a fralda de um aluno cadeirante, a escola teve que contar com a doação de uma mesa de professor de outra escola e fazer adaptação com colchonete; além disso, não havia lenço umedecido, luva ou outro recurso para realizar as trocas e a higienização.

Os equipamentos necessários foram considerados adequados quando os gestores informaram que a escola tinha o suficiente para o atendimento aos alunos PAEE, mesmo que limitando esses equipamentos à sala de recursos multifuncionais (SRM). Entre os equipamentos destacados estão computadores, impressora comum, impressora multifuncional, lupas, jogos em braille, materiais em braille e Libras, softwares diversos, bola com guizo, etc., conforme estabelecido em leis (Politica Nacional de Educação Especial na Perspectiva da Educação Inclusiva, de 2008; Decreto n. 7.611, de 17 de novembro de 2011). Todas as escolas foram pontuadas nesse item.

\section{Refeitório}

Foram itens de análise dessa categoria: tamanho de mesas e cadeiras, distância entre os móveis, número de crianças por mesa, utensílios em bom estado de conservação e necessidade de a criança esperar a mesa. 
TABELA 4

PONTUAÇÕES ATRIBUÍDAS ÀS CONDIÇÕES DOS REFEITÓRIOS

\begin{tabular}{|c|c|c|c|c|c|c|c|c|c|c|c|c|c|c|c|c|}
\hline \multicolumn{17}{|c|}{ ESCOLAS } \\
\hline ITENS & 1 & 2 & 3 & 4 & 5 & 6 & 7 & 8 & 9 & 10 & 11 & 12 & 13 & 14 & 15 & 16 \\
\hline $\begin{array}{c}\text { Tamanho de mesas } \\
\text { e cadeiras }\end{array}$ & 2,0 & 2,0 & 2,0 & 2,0 & 2,0 & 2,0 & 2,0 & 2,0 & 2,0 & 2,0 & 2,0 & 2,0 & 2,0 & 2,0 & 2,0 & 2,0 \\
\hline $\begin{array}{c}\text { Distância entre os } \\
\text { móveis }\end{array}$ & 2,0 & 2,0 & 2,0 & 2,0 & 2,0 & 2,0 & 2,0 & 2,0 & 2,0 & 0 & 2,0 & 0 & 2,0 & 2,0 & 2,0 & 2,0 \\
\hline $\begin{array}{c}\text { Número de } \\
\text { crianças por mesa }\end{array}$ & 2,0 & 2,0 & 2,0 & 2,0 & 2,0 & 2,0 & 2,0 & 2,0 & 0 & 2,0 & 0 & 2,0 & 2,0 & 2,0 & 2,0 & 2,0 \\
\hline $\begin{array}{l}\text { Utensílios em } \\
\text { bom estado de } \\
\text { conservação }\end{array}$ & 2,0 & 2,0 & 2,0 & 2,0 & 2,0 & 2,0 & 2,0 & 2,0 & 2,0 & 2,0 & 2,0 & 2,0 & 2,0 & 2,0 & 2,0 & 2,0 \\
\hline $\begin{array}{l}\text { Necessidade de a } \\
\text { criança esperar à } \\
\text { mesa }\end{array}$ & 2,0 & 2,0 & 2,0 & 2,0 & 2,0 & 2,0 & 2,0 & 2,0 & 2,0 & 2,0 & 2,0 & 2,0 & 2,0 & 2,0 & 2,0 & 2,0 \\
\hline NOTA & 10 & 10 & 10 & 10 & 10 & 10 & 10 & 10 & 8,0 & 8,0 & 8,0 & 8,0 & 10 & 10 & 10 & 10 \\
\hline
\end{tabular}

Fonte: Elaborado pelas autoras com os dados observados nas escolas.

Observou-se que os refeitórios das escolas ou eram em locais específicos, fechados, ou no próprio pátio da escola. A média das escolas nessa categoria foi de 9,5 pontos. Doze escolas receberam pontuação máxima (10 pontos) e quatro (E9, E10, E11 e E12), 8 pontos.

O tamanho das mesas e cadeiras foi considerado adequado quando esses móveis tinham dimensões que permitissem seu uso com conforto (MEC, 2009) em relação ao tamanho das crianças. Todas as escolas atenderam ao critério.

A distância entre os móveis foi classificada como adequada quando se observou ser possível circular e manobrar cadeira de rodas entre as mesas do refeitório (MEC, 2009). Para Calado (2006), a distância ideal entre as mesas é de 1,20 metros, e sua disposição deve ser de forma ortogonal, com posicionamento em ângulo reto. Em duas escolas (E10 e E12), o número de crianças por mesas foi avaliado como inadequado, uma vez que a disposição das mesas e bancos tinha configuração apertada em relação ao espaço disponível, o que dificultava a circulação e acomodação dos alunos com deficiência.

O número de crianças por mesa foi considerado adequado quando os alunos conseguiam se acomodar em distância que permitia a movimentação livre dos braços para realizar a refeição. No entanto, em duas escolas (E9 e E11), o número de crianças por mesas foi avaliado como inadequado. $\mathrm{O}$ projeto arquitetônico acessível deve se preocupar com a quantidade de usuários que vão utilizar o ambiente, visto que esse número pode aumentar com o tempo (Evangelo, 2014).

Os utensílios foram considerados em bom estado de conservação quando não estavam deteriorados, quebrados ou sujos. A maioria dos utensílios utilizados pelas escolas era de plástico, mas todos foram encontrados em boas condições de uso. Entretanto, destaca-se que, para os alunos com deficiência, muitos dos utensílios a serem utilizados devem ter adaptações, como colheres com cabo angulado, prato com fixador em ventosa, copo com duas alças, etc. (Calado, 2006), de modo a proporcionar ao aluno com deficiência melhores condições na hora de se alimentar. Essas adaptações, do campo da tecnologia assistiva, são simples e de baixo custo, mas quase sempre difíceis de serem encontradas.

A necessidade de a criança esperar à mesa foi considerada atendida quando relatada pelos gestores. Verificou-se que, em todas as escolas, elas eram atendidas de acordo com suas necessidades. Segundo os entrevistados, os alunos sem deficiência formavam fila para pegar sua comida ou, como observado na escola (E13), as próprias crianças se serviam, possibilitando autonomia e independência aos alunos, além de conscientizá-los sobre o desperdício, pois cada um se servia do quanto pretendia comer. Todavia, o aluno com deficiência recebia auxílio para se servir e se alimentar, quando não tinha autonomia para isso. 
Evangelo (2014), ao analisar as condições de 48 escolas do munícipio de Viçosa, Minas Gerais, realizou visitas in loco para verificar condições de acessibilidade de três escolas que tinham aluno com deficiência, consideradas acessíveis pela Secretaria de Educação ou pelos seus dirigentes. Entre os itens avaliados nessas três escolas, somente uma tinha refeitório com dimensões satisfatórias para o uso das crianças, enquanto nas outras duas os espaços eram pequenos para a quantidade de crianças, ou suas mesas e cadeiras eram muito altas.

\section{Outros recursos}

Foram itens de análise dessa categoria: atividades desenhadas no chão, cartazes ou mural com trabalhos, palco, sala de vídeo, biblioteca, elevador, atividades diferenciadas e parquinho.

TABELA 5

\section{PONTUAÇÕES ATRIBUÍDAS A OUTROS RECURSOS ESCOLARES}

\begin{tabular}{|c|c|c|c|c|c|c|c|c|c|c|c|c|c|c|c|c|}
\hline \multicolumn{17}{|c|}{ ESCOLAS } \\
\hline ITENS & 1 & 2 & 3 & 4 & 5 & 6 & 7 & 8 & 9 & 10 & 11 & 12 & 13 & 14 & 15 & 16 \\
\hline $\begin{array}{c}\text { Atividades } \\
\text { desenhadas no } \\
\text { chão }\end{array}$ & 1,0 & 0 & 0 & 0 & 1,0 & 0 & 0 & 0 & 1,0 & 0 & 1,0 & 0 & 1,0 & 1,0 & 0 & 0 \\
\hline $\begin{array}{l}\text { Cartazes ou } \\
\text { mural com } \\
\text { trabalhos }\end{array}$ & 1,0 & 0 & 0 & 0 & 1,0 & 1,0 & 1,0 & 1,0 & 1,0 & 1,0 & 1,0 & 1,0 & 1,0 & 1,0 & 1,0 & 1,0 \\
\hline Palco & 1,0 & 0 & 1,0 & 0 & 1,0 & 1,0 & 1,0 & 0 & 1,0 & 1,0 & 0 & 1,0 & 1,0 & 1,0 & 0 & 1,0 \\
\hline Sala de vídeo & 1,5 & 1,5 & 1,5 & 0 & 1,5 & 1,5 & 1,5 & 1,5 & 1,5 & 1,5 & 0 & 1,5 & 1,5 & 1,5 & 1,5 & 1,5 \\
\hline Biblioteca & 1,5 & 1,5 & 1,5 & 1,5 & 1,5 & 1,5 & 1,5 & 1,5 & 1,5 & 1,5 & 1,5 & 1,5 & 1,5 & 1,5 & 1,5 & 1,5 \\
\hline Elevador & 0 & 0 & 0 & 1,0 & 0 & 0 & 0 & 0 & 0 & 0 & 0 & 0 & 0 & 0 & 0 & 0 \\
\hline $\begin{array}{l}\text { Atividades } \\
\text { diferenciadas }\end{array}$ & 0 & 0 & 1,5 & 0 & 0 & 1,5 & 1,5 & 0 & 1,5 & 1,5 & 0 & 1,5 & 0 & 0 & 1,5 & 0 \\
\hline Parquinho & 1,5 & 0 & 1,5 & 0 & 0 & 1,5 & 0 & 0 & 1,5 & 1,5 & 1,5 & 1,5 & 1,5 & 1,5 & 1,5 & 1,5 \\
\hline NOTA & 7,5 & 3,0 & 7,0 & 2,5 & 6,0 & 8,0 & 6,5 & 4,0 & 9,0 & 8,0 & 5,0 & 8,0 & 7,5 & 7,5 & 7,0 & 6,5 \\
\hline
\end{tabular}

Fonte: Elaborado pelas autoras com os dados observados nas escolas.

Receberam pontuação as escolas que apresentavam esses recursos. A média nessa categoria foi de 6,4 pontos, com a escola 4 recebendo a menor pontuação (2,5 pontos) e a 9, a mais alta ( 9,0 pontos). $\mathrm{O}$ item biblioteca foi encontrado em todas as escolas e, por isso, todas foram pontuadas, enquanto o item elevador só foi pontuado na escola 4.

Em cinco escolas foram encontradas atividades desenhadas no chão (E1, E5, E9, E13 e E14): amarelinha, caracol e tabuleiro de dama.

Foram verificadas atividades desenvolvidas pelos alunos em cartazes ou murais de 13 escolas (E1, E5, E6, E7, E8, E9, E10, E11, E12, E13, E14, E 15 e E16).

O palco fazia parte do pátio de 11 escolas (E1, E3, E5, E6, E7, E9, E10, E12, E13, E14, E16). No entanto, alguns desses espaços só possibilitavam o acesso por meio de escadas. Em contrapartida, a escola 6 tinha até a instalação de placa de "Palco Adaptado", recebida em 2013.

A sala de vídeo foi identificada em 14 escolas (E1, E2, E3, E5, E6, E7, E8, E9, E10, E12, E13, E14, E15 e E16), considerando-se as que apresentavam infraestrutura específica e aquelas que dispunham de carrinho de vídeo itinerante, para realização da atividade na própria sala de aula.

Em todas as escolas foram encontradas bibliotecas, apesar de se diferenciarem em termos de ambiente confortável e ambiente apertado, refutando a média do país apresentada pelo Censo Escolar de 2017, em que bibliotecas e/ou salas de leitura estavam presentes em 54,3\% dos estabelecimentos de ensino fundamental (MEC, 2018). 
Das 16 escolas visitadas, 14 estão instaladas em construção térrea. Das duas escolas que apresentavam mais de um pavimento, apenas uma dispõe de elevador (E4); essa, por sua vez, estava utilizando imóvel alugado (antiga escola de cursinhos pré-vestibular) enquanto esperava a reforma do prédio da prefeitura.

No item atividades diferenciadas, foram pontuadas as escolas que informaram oferecer atividades extraclasse aos seus alunos (E3, E6, E7, E9, E10, E12 e E15). Foram ações promovidas pelas escolas: aula de música (violão, flauta), aula de dança (capoeira), aula de informática, xadrez, capoeira e banda escolar, ofertadas no contraturno escolar de forma optativa aos interessados.

O parquinho foi considerado presente nas escolas que tinham local constituído com pelo menos um brinquedo e banco de areia, estar em manutenção e/ou ter parceria com a Emei. Parquinhos desativados foram excluídos da pontuação. O item sobressaiu em 11 das 16 escolas avaliadas (E1, E3, E7, E8, E9, E10, E11, E12, E13, E14, E15 e E16), abarcando 68\% delas e destacando-se acima da média do país, que é de 27,5\% (Inep, 2018).

Entretanto, conforme destacou a G10, mesmo a escola tendo parquinho, nenhum brinquedo era adaptado ao aluno com deficiência. Como declara Carvalho (2008), as escolas devem disponibilizar brinquedos que permitam a utilização das pessoas com deficiência, com assentos articuláveis e material firme, não escorregadio, sem arestas vivas e apoio nos braços (dependendo do brinquedo), corrimãos, grades de proteção etc. Os pisos ideais desses locais devem ser os não sólidos, como de terra, grama e areia, pois servem para o amortecimento de quedas em escorregadores, dentre outros. Também se deve optar por grama sintética, piso de borracha ou outro que permita o acesso do aluno que usa cadeira de rodas (Carvalho, 2008).

\section{Análise geral das escolas}

A partir das categorias e itens avaliados, foi realizada uma análise geral das escolas, conforme pontuações exibidas no Gráfico 1.

\section{GRÁFICO 1}

\section{CLASSIFICAÇÃO FINAL DAS ESCOLAS}

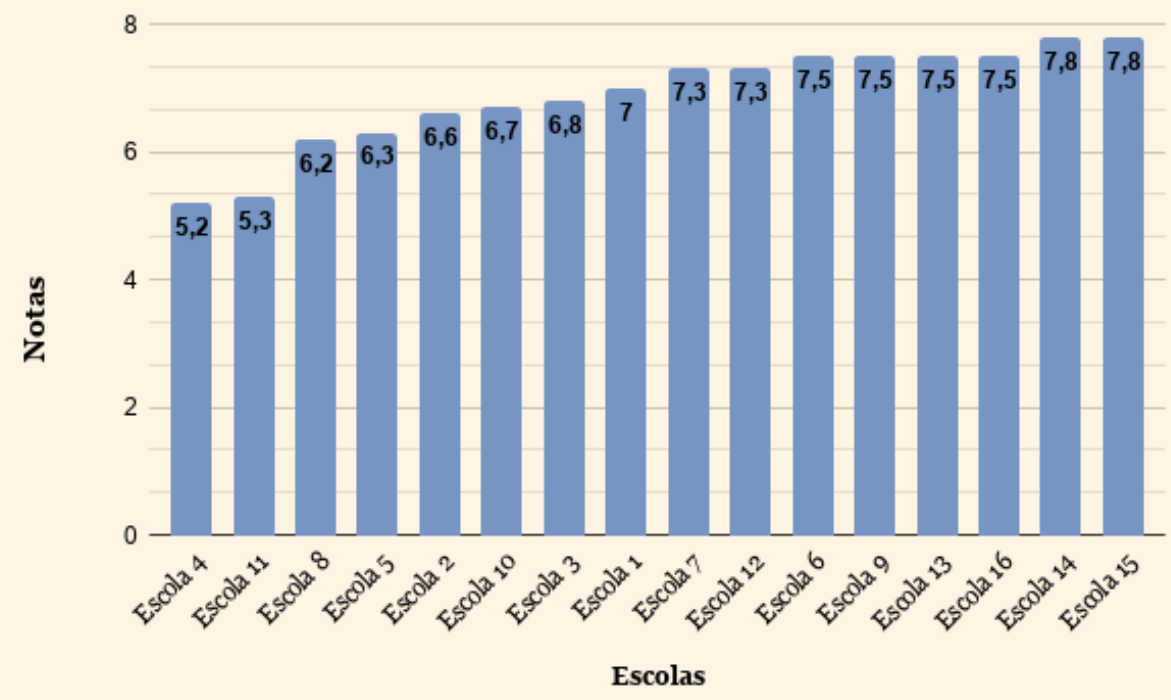

Fonte: Elaborado pelas autoras com os dados obtidos pelo roteiro de observação do espaço físico e recursos inclusivos do contexto escolar.

A análise da infraestrutura física pelo roteiro de observação do espaço físico e recursos inclusivos do contexto escolar resultou na média de 6,8 pontos. A escola quatro teve a menor pontuação ( 5,2 pontos) e as escolas 14 e 15, a maior (7,8 pontos), divergindo em 2,6 pontos. Para classificação da infraestrutura, as escolas com pontuações entre 0 e 5,0 foram consideradas inadequadas; de 5,1 a 7,9, parcialmente adequadas; e de 8,0 a 10, adequadas. Sendo assim, ao ponderar as dimensões analisadas nas escolas 
e a inexistência de alguns itens essenciais, todas as 16 escolas, incluindo a escola 7, construída após a elaboração do manual de acessibilidade de 2009, foram classificadas como parcialmente adequadas ao atendimento de alunos PAEE, demonstrando a necessidade de adequações e/ou adaptações de tais espaços para que consigam a inclusão integral de todos os alunos.

Entretanto, as análises realizadas levaram em conta as modificações necessárias ao atendimento do PAEE de modogeral, ou seja, que deveriam atender a todos, independentemente de suas características. Sendo assim, as escolas podem estar parcialmente adequadas aos alunos nelas matriculados, mas não necessariamente adaptadas a outros alunos PAEE que possam vir a utilizá-las.

Os resultados obtidos com a soma das pontuações de cada escola refutam o ponto de vista dos gestores sobre as condições da infraestrutura escolar, visto que, dos 16 gestores, 43,7\% $(\mathrm{n}=7)$ declararam a infraestrutura física como satisfatória (G2, G4, G6, G8, G11, G12, G13), 43,7\% ( $\mathrm{n}=7$ ) informaram a infraestrutura física como inadequada (G1, G3, G5, G7, G10, G14, G15) e 12,5\% ( $\mathrm{n}=2)$ consideraram-na adequada aos alunos PAEE já atendidos (G9, G16).

Segundo os gestores, as escolas com a infraestrutura física satisfatória destacaram-se pelas adequações realizadas para a eliminação de obstáculos e aquisição de materiais, softwares e laptops. Desse modo, pode-se pressupor que escolas não necessariamente vistas como totalmente adequadas, em função de adaptações e recursos que têm recebido, consideraram que a infraestrutura atende às necessidades desse público escolar. Em contrapartida, as escolas com espaço físico inadequado ainda carecem de adaptações, tais como mudança da planta escolar, ampliação e melhoria da infraestrutura física, maior disponibilidade de recursos materiais e maior oferta de materiais adaptados.

Além disso, observou-se que as escolas ainda necessitam de piso antiderrapante e tátil, melhor sinalização, eliminação de obstáculos, ampliação das portas, melhoria da infraestrutura escolar, maior disponibilidade de recursos materiais e materiais adaptados, principalmente na sala comum. Porém, em todas foram encontrados pelo menos 14 itens ou mais adaptados aos alunos com deficiência.

\section{Considerações finais}

Com a crescente necessidade de atendimento a todos os alunos, independentemente de suas características, a presente pesquisa teve como objetivo verificar as condições da infraestrutura física das escolas de um sistema municipal de ensino fundamental, considerando os alunos PAEE.

Os resultados do roteiro de observação do espaço físico e recursos inclusivos do contexto escolar possibilitaram a classificação das 16 escolas como parcialmente adequadas ao atendimento dos alunos, refutando o ponto de vista dos gestores sobre a condição da infraestrutura escolar, que foi considerada satisfatória por $43,7 \%$ deles $(n=7)$, inadequada por $43,7 \%(n=7)$ e adequada aos alunos PAEE já atendidos por $12,5 \%(n=2)$. No entanto, os principais pontos a serem melhorados foram ampliação e melhoria da infraestrutura física e maior disponibilidade de recursos materiais e recursos adaptados, principalmente na classe comum.

Como limitações do estudo, destaca-se a impossibilidade de identificação das necessidades de adaptações das escolas para cada aluno PAEE, devido à escolha do instrumento. Sugere-se que as próximas pesquisas possibilitem que os próprios gestores escolares também preencham o roteiro de observação do espaço físico e recursos inclusivos do contexto escolar para que se consiga identificar a visão desses sujeitos em relação à qualidade da escola observada, comparando-a com o roteiro de observação preenchido pela própria pesquisadora. Desse modo, acredita-se que o reconhecimento de tais dados seja de fundamental importância para que cada escola e o sistema municipal de ensino consigam traçar um plano de ação para pensar as adequações a curto, médio e longo prazos para cada uma delas, começando pelas mais comprometidas. Ademais, os resultados encontrados respaldam outras pesquisas que, ao analisarem as condições da infraestrutura escolar, verificaram que nenhuma escola estava adaptada em todos os itens avaliados, tornando as condições de acessibilidade ainda injustas. 


\section{Referências}

Bardin, L. (2011). Análise de conteúdo. Edições 70.

Basei, A. P., \& Cavasini, G. F. (2015). A inclusão escolar e as condições de acessibilidade: Um estudo preliminar na região sudoeste do Paraná. Cinergis, 16(1), 27-32.

Calado, G. C. (2006). Acessibilidade no ambiente escolar: Reflexões com base no estudo de duas escolas municipais de Natal-RN. [Dissertação de Mestrado]. Centro de Tecnologia, Universidade Federal do Rio Grande do Norte. UFRN. https://repositorio.ufrn.br/handle/123456789/12416

Capellini, V. L. M. F. (2018). Avaliação da qualidade da educação ofertada aos alunos público-alvo da educação especial em escolas públicas da Comarca de Bauru. [Relatório de Pesquisa submetido à Fapesp, São Paulo].

Carvalho, T. C. P. de. (2008). Arquitetura escolar inclusiva: Construindo espaços para educação infantil. [Tese de Doutorado]. Escola de Engenharia de São Carlos, Universidade de São Paulo. https:/www.teses.usp.br/teses/ disponiveis/18/18141/tde-06022009-150902/publico/tese_telma_cristina_carvalho.pdf

Castro, F. F. M. de. (2000). A importância do espaço no processo de ensino. Pós - Revista do Programa de Pós- Graduação em Arquitetura e Urbanismo da FAUUSP, 9, 176-189.

Castro, G. G. de, Abrahão, C. A. F., Nunes, Â. X., Nascimento, L. C. G. do, \& Figueiredo, G. L. A. (2018, janeiro-março). Inclusão de alunos com deficiências em escolas da rede estadual: Um estudo sobre acessibilidade e adaptações estruturais. Revista Educação Especial, 31(60), 93-106.

Corrêa, P. M. (2010). Elaboração de um protocolo para avaliação de acessibilidade física em escolas da educação infantil. [Dissertação de Mestrado]. Faculdade de Filosofia e Ciências, Universidade Estadual Paulista "Júlio de Mesquita Filho", Marília. https://repositorio.unesp.br/handle/11449/91190

Corrêa, P. M., \& Manzini, E. J. (2012, abril/junho). Um estudo sobre as condições de acessibilidade em pré-escolas. Revista Brasileira de Educação Especial, 18(2), 213-230.

Cozby, Paul C. (2003). Métodos de pesquisa em ciências do comportamento (P. I. C. Gomide, E. Otta Trad.). Atlas.

Decreto n. 7.611, de 17 de novembro de 2011. Dispõe sobre a educação especial, o atendimento educacional especializado e dá outras providências. Presidência da República. Brasília.

Evangelo, L. S. (2014). Avaliação da acessibilidade e mobilidade arquitetônica em escolas de ensino fundamental de Viçosa-MG. [Dissertação de Mestrado]. Universidade Federal de Viçosa. https://www.locus.ufv.br/ handle/123456789/6571

Fonseca, T. da S., Freitas, C. S. C., \& Negreiros, F. (2018, julho/setembro). Psicologia escolar e educação inclusiva: A atuação junto aos professores. Revista Brasileira de Educação Especial, 24(3), 427-440.

Gallo, E. C., Orso, K. D, \& Fiório, F. B. (2011). Análise da acessibilidade das pessoas com deficiência física nas escolas de Chapecó-SC e o papel do fisioterapeuta no ambiente escolar. O Mundo da Saúde, 35(2), 201-207.

Gil, A. C. (2010). Como elaborar projetos de pesquisa. Atlas.

Instituto Brasileiro de Geografia e Estatística. (2017). https://cidades.ibge.gov.br/brasil/sp/bauru/panorama

Instituto Nacional para a Reabilitação. (2014). Desenho universal. http://www.inr.pt/content/1/5/desenho-universal.

Kimura, S. (2008). Geografa no ensino básico: Questões e propostas. Contexto.

Kowaltowski, D. C. C. K. (2014). Arquitetura escolar: O projeto do ambiente de ensino. Oficina de Textos.

Lei n. 9.394, de 20 de dezembro de 1996. Estabelece as diretrizes e bases da educação nacional. Diário Oficial da União, Brasília, 1996.

Manzini, E. J., \& Corrêa, P. M. (2008). Avaliação da acessibilidade em escolas do ensino fundamental usando a tecnologia digital. [Apresentação de comunicação]. Reunião Anual da Associação Nacional de Pós-Graduação e Pesquisa em Educação [Anped], Caxambu, MG, Brasil.

Médice, J., De Vitta, F. C. F., De Conti, M. H. S., Zaniolo, L. O., \& De Vitta, A. (2015). Acessibilidade nas escolas de ensino fundamental de um município da região oeste de São Paulo. Cadernos Brasileiros de Terapia Ocupacional, 23(3), 581-588.

Mendes, E. G. (2002). A inclusão escolar em creches desenvolvendo procedimentos para avaliação de políticas e formação de educadores. [Projeto de Bolsista Produtividade aprovado pelo CNPq, São Carlos-SP]. Mimeografado. 
Ministério da Educação. (2009). Manual de acessibilidade espacial para escolas: O direito à escola acessível! Secretaria de Educação Especial. https://www.mpdft.mp.br/portal/pdf/rede_urbanidade/ Manual_ acessibilidade_espacial_escolas.pdf

Ministério da Educação. (2013). Documento Orientador: Programa Escola Acessível. Secretaria de Educação Continuada, Alfabetização, Diversidade e Inclusão. http://portal.mec.gov.br/arquivos/pdf/ politicaeducespecial.pdf

Ministério da Educação. (2018). Censo Escolar 2017: Notas estatísticas. Instituto Nacional de Estudos e Pesquisas Educacionais Anísio Teixeira.

Ministério da Educação. (2019). Censo Escolar 2018: Notas estatísticas. Instituto Nacional de Estudos e Pesquisas Educacionais Anísio Teixeira.

Miron, E. M., \& Costa, M. da P. R. da. (2014, janeiro/março). Barreiras físicas e o acesso às aulas de educação física. Pensar a Prática, 17(2), 377-394.

Monteiro, J. de S., \& Silva, D. P. da. (2015, setembro/dezembro). A influência da estrutura escolar no processo de ensino-aprendizagem: Uma análise baseada nas experiências do estágio supervisionado em Geografia. Geografia Ensino \& Pesquisa, 19(3), 19-28.

Moraes, M. G. de. (2007). Acessibilidade e inclusão social em escolas. [Trabalho de Conclusão de Curso]. Faculdade de Ciências, Universidade Estadual Paulista "Júlio de Mesquita Filho", Bauru.

Organização das Nações Unidas para a Educação, Ciência e Cultura. (1990). Declaração Mundial sobre Educação para Todos: Plano de ação para satisfazer as necessidades básicas de aprendizagem. Unesco.

Organização das Nações Unidas para a Educação, Ciência e Cultura. (2008). 48th International Conference on Education - Conclusions and recommendations. IBE.

Organização das Nações Unidas para a Educação, Ciência e Cultura, \& Ministério da Educação. (1994). Declaração de Salamanca e linha de ação sobre necessidades educativas especiais. Coordenadoria Nacional para Integração da Pessoa com Deficiência (Corde).

Organização das Nações Unidas para a Educação, Ciência e Cultura. (2019). Qualidade da infraestrutura das escolas públicas do ensino fundamental no Brasil. Unesco.

Política Nacional de Educação Especial. (1994). Ministério da Educação. Secretaria de Educação Especial.

Política Nacional de Educação Especial na Perspectiva da Educação Inclusiva. (2008). Ministério da Educação. Secretaria de Educação Especial.

Resolução n. 466, de 12 de dezembro de 2012. Aprova diretrizes e normas regulamentadoras de pesquisas envolvendo seres humanos. Brasília: Ministério da Saúde. Conselho Nacional de Saúde.

Roquejani, T. C., Capellini, V. L. M. F., \& Fonseca, K. de A. (2018). O desenho universal para aprendizagem em contextos inclusivos do ensino fundamental. In A. A. S. Oliveira, K. de A. Fonseca, \& M. R. dos Reis (Orgs.), Formação de professores e práticas educacionais inclusivas (pp. 59-77). Editora CRV.

Sá, J. dos S., \& Werle, F. O. C. (2017, abril/junho). Infraestrutura escolar e espaço físico em educação: O estado da arte. Cadernos de Pesquisa, 47(164), 386-413.

Santos, C. E. M. dos. (2019). Da infraestrutura física às práticas pedagógicas: Desafios da escola frente ao aluno público-alvo da educação especial. [Dissertação de Mestrado]. Faculdade de Ciências, Universidade Estadual Paulista "Júlio de Mesquita Filho", Bauru. https://repositorio.unesp.br/handle/11449/181630

Satyro, N., \& Soares, S. (2007). A infraestrutura das escolas brasileiras de ensino fundamental: Um estudo com base nos censos escolares de 1997 a 2005. Ipea.

Silva Filho, D. M. da, \& Kassar, M. de C. M. (2019). Acessibilidade nas escolas como uma questão de direitos humanos. Revista Educação Especial, 32(27), 1-19.

Soares Neto, J. J., Jesus, G. R. de, Karino, C. A., \& Andrade, D. F. de. (2012, janeiro/março). Uma escala para medir a infraestrutura escolar. Estudos em Avaliação Educacional, 24(54), 78-99.

Tada, I. N. C., Lima, V. A. A. de, Melo, T. G., \& Correio, D. Y. V. T. (2012, janeiro/março). Conhecendo o processo de inclusão escolar em Porto Velho-RO. Psicologia: Teoria e Pesquisa, 28(1), 65-69.

Teixeira, M. T., \& Reis, M. F. (2012, maio/agosto). A organização do espaço em sala de aula e suas implicações na aprendizagem cooperativa. Meta: Avaliação, 4(11), 162-187. 


\section{Nota sobre autoria}

Este artigo faz parte da dissertação de mestrado Da infraestrutura física às práticas pedagógicas: desafios da escola frente ao aluno público-alvo da educação especial, desenvolvida primeira autora, Camila Elidia Messias dos Santos, responsável pela coleta, descrição e análise dos dados, e orientada pela segunda autora, Vera Lucia Messias Fialho Capellini, que participou da análise dos dados e revisão do artigo.

\section{Disponibilidade de dados}

As autoras não disponibilizam os dados desta pesquisa, pois novos estudos ainda estão sendo desenvolvidos. Sendo assim, após o término, os dados poderão ser disponibilizados mediante consulta aos autores.

\section{Como citar este artigo}

Santos, C. E. M. dos, \& Capellini, V. L. M. F. (2021). Inclusão escolar e infraestrutura física de escolas de ensino fundamental. Cadernos de Pesquisa, 51, Artigo e07167. https://doi.org/10.1590/198053147167 